\title{
Strengthening All Our Relations
}

\author{
Sylvia Moore
}

\begin{abstract}
This article is a reflection on an education research project, based in a Mi'kmaw community, which brought together staff and students from North Queens School with community members from Wildcat First Nation to collaborate in a project involving Atlantic salmon and bass in the Mi'kmaw community. Framed in the Mi'kmaw concept of msit no'kmaq (all my relations), the writing explores four strands of interconnectivity that exemplify how engaged scholarship with Indigenous communities is based in respectful and reciprocal relationships. The four strands represent relationships: between adults, adults and children, humans and salmon, and people and the land.
\end{abstract}

KEYWORDS collaborative research; interconnectivity; relationships; engaging community

This is a reflection on research that brought together the members of the Mi'kmaw community of Wildcat First Nation as well as the staff and students of North Queens School in southwest Nova Scotia. The research, extending over a period of eight weeks in the spring of 2008, examined the work of the K-6 school staff and the Mi'kmaw community members in centering and legitimating Mi'kmaw knowledge in education. The focus of the collaborative work was a salmon project in which Atlantic salmon were raised and then released into the local Wildcat River. The project was based in Wildcat First Nation where the hatching of three hundred salmon eggs could be observed and where participants were invited to share knowledge through stories (Moore, 2017).

The collaborative research team involved Todd Labrador, Jamie Jermey, Tina Dixon, shalan joudry, and Sylvia Moore. Todd is an Elder and traditional teacher, Jamie is a traditional teacher who regularly came to the school to work with teachers and students, and Tina was the Aboriginal Student Support Worker. Todd, Tina, and Jamie are all members of Wildcat First Nation. Shalan is a traditional storyteller who is a member of Bear River First Nation and she is my daughter. At the time of the salmon project, I was a teacher and school administrator at North Queens Community School and was undertaking research as part of my PhD studies in education. Todd, shalan, Jamie, Tina, and I had all worked together for several years on various projects, guided by valuing children and youth as the heart of a nation. This particular research contributed to our on-going efforts to promote culturally relevant curriculum in the education of our children and grandchildren, and it also fulfilled my university research requirements. The research developed into long-term sustained work between the school staff and the Mi'kmaw community whereby the groups continued to collaborate in an annual salmon project. 
I used Indigenous research methodology by promoting the well being of the community (Jimenez Estrada, 2005; Smith, 1999; Rigney, 1999; Kovach, 2005) and by privileging Indigenous scholars and theories in framing and analyzing the research (Battiste and Henderson, 2000). ${ }^{1}$ The conceptual framework for this research was msit no'kmaq, a Mi'kmaw phrase acknowledging "all my relations." Elder Albert Marshall confirms that "our [Mi'kmaw] teachings are based on the interconnectedness of all things" (Collaborative Salmon Initiative Planning Committee, 2007, p. 17) and relationships are at the very core of this connectedness. Several Indigenous researchers address the importance of the researcher's relations. Jean Graveline (1998) refers to the researcher-in-relation, Margaret Kovach (2009) discusses the relational skills of researchers, and Sean Wilson (2008) stresses researcher accountability to all our relations. Vine Deloria (1999) states that relationships can be used as a research tool.

The foundation of the work between school educators and Mi'kmaw community members was respectful and reciprocal relations in working together in the salmon project. However, there were other relationships that also reflect the ways in which people were engaged in the research. These included relationships between adults and children, humans and the salmon, and participants and the land. These four categories of relationships are like the strands of a braid that are interwoven and together represent strengthened research engagement. In this article, I reflect on each of those four strands and explore the nature of those relationships.

\section{Strand One: Relationships Among the Adults}

At the center of this research project were the three hundred salmon eggs obtained from a local federal fish hatchery in the spring of 2008 and placed in a glass tank in Wildcat First Nation where they were accessible to the participants. Staff and students from the school travelled to the community to learn about the salmon by observing them as they hatched and by participating in learning activities, including the salmon release. Staff, students, parents, and the public were also invited to participate in weekly learning circles to learn more about salmon through the shared stories of Elders, traditional teachers, biologists, and circle participants. Lori Lambert (2014) describes circles as inclusive and within sharing circles all participants are viewed as equal (p. 10).

Each learning circle began with Todd smudging the area and offering a prayer. Prayer is "a cultural learning process which promotes the principles of respect, reverence, responsibility, and reciprocity" (Archibald, 1997, p. 1-2). During the sharing circles, people told stories about catching salmon, preparing and eating salmon, the health of the salmon population, the life cycle of the salmon, and the state of the local river. All people had an interest in the salmon and all had stories to tell. The people and the salmon are both part of the life on the land in this region. The learning circles honoured people as everyone listened and everyone's voice was valued in the learning.

The circles were occasions for talking and listening, and it was through this listening and

\footnotetext{
1 The "I" in this writing is inextricably connected to, and reflects the work of, the research team that included Todd Labrador, Tina Dixon, shalan joudry, Jamie Jermey, and myself.
}

Engaged Scholar Journal: Community-Engaged Research, Teaching and Learning 
sharing of stories that we got to know one another better. In considering the skills researchers require to work collaboratively with Indigenous communities, Kovach (2009) writes, "[T] hey know when to step up and when to step back...my experience tells me that these folks have humility, a sense of humor, and are attuned_all of which are relational skills (p. 65)." As I reflect on the salmon project, I realize that such skills were reflected in the relationships of adults involved in the salmon project. Humility meant that people came into the learning circles with an open mind and a good heart to learn from others. There was laughter in the circles, which eased tension and contributed to the good-natured atmosphere of the event. Being attuned to other people requires respectful listening. Evelyn Steinhauer (2002) quotes a Cree manual when she writes: "By listening intently you show honor, consider the well being of others, and treat others with kindness and courtesy" (p. 73).

Having the salmon project in the community rather than at the school was important because it located the community as the center of learning. It was also a way to welcome increased parent involvement in education. Mi'kmaw Elder Murdena Marshall reminded me, "Remember that it was only until recently that Mi'kmaw parents were allowed to be in schools. Parents are still not comfortable in schools" (personal communication, October 23, 2009). In this research, the school staff was reaching out to Wildcat First Nation to learn from them and with them. This validated and legitimated the knowledge of community members (Moore, 2012). The research was an opportunity for teachers themselves to learn more about Mi'kmaw ways of doing, knowing, and being.

Jamie later reflected on the on-going relationship between community members and teachers:

We cannot look at the participants in work such as the salmon project as Native or non-Native. We all want to teach the youth. We all want to make life better for others. But our community has to heal. Teachers can help us heal by teaching our history in the schools. We talk, we teach, and we heal. (personal communication, August 31, 2009)

The relationships between people were nurtured through sharing in a number of different ways. We shared the experience of watching the salmon eggs hatch, we shared stories, and we shared food at the end of each learning circle and after the salmon release. There was also sharing of the responsibility of releasing salmon into the river. Each person could release some of the salmon and participate in the ceremony. Sharing is a way of Mi'kmaw life that includes materials, considerations, friendship, and knowledge (Prosper, Paulette, and Davis, 2004, p. 8).

The research drew people in and engaged them by the very nature of the activity. The community was inviting and the project was open to all people. "Learning for all," as Todd once described it. I have often heard him quote his father, Hereditary Chief and Elder Charlie Labrador: "If you look underground you will see that all the roots of all the trees and plants are spread out and touching one another. It is as if they are holding hands. We, too, need one 
another and reach out through our relationships in the world to support one another." The feeling of holding hands was synonymous with a sense that we were all in the salmon project together and supporting one another in the learning experience.

\section{Strand Two: Relationships Between the People and the Salmon}

The people who joined in the project were interested in the salmon and thus the fish became a connector of the participants. People would stand at the tank watching the salmon, sometimes in silence and on other occasions they talked to the salmon or other people who were also watching. The change in salmon eggs, as they hatched, was difficult to discern. When they

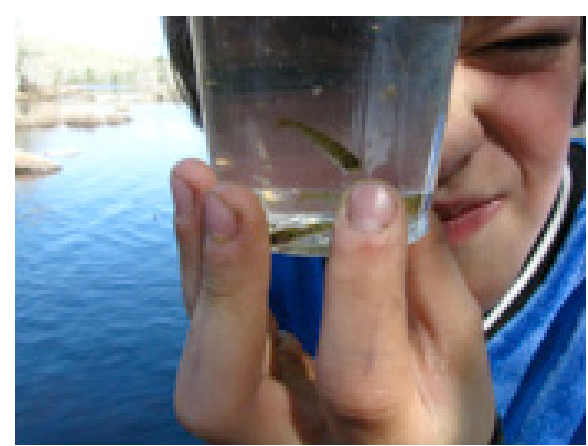

Figure 1: Student holding salmon (May 18, 2008) Photo by: Salmon project team began to hatch, each salmon was held close to the bottom by the weight of the egg sac still attached to it. The sac not only nourished the salmon until it was old enough to find its own food, but the weight also kept each one safely hidden amongst the rocks on the bottom of the tank. The viewers had to be keen to see the small fish.

Gathering in the room with the salmon eggs and sharing talk was a celebration for both the new life that was emerging and for the opportunity that we, as humans, had to witness it. Albert Marshall describes the salmon as a "revered species" that has been both a food source and "used in spiritual celebrations as an expression of gratitude to the Creator for what he gave to us" (p. 12). When I talked with Albert about the salmon project, he explained that learning about something is "surface learning." But when we learn from something, we are in a respectful relationship with the entity and the learning is deep (personal communication, October 23, 2009). Shawn Wilson (2001) explains that knowledge is relational through relationships with all of creation: "It is with the cosmos, it is with the animals, with the plants, with the earth that we share this knowledge" (p. 177).

Tina explained to me the impact the salmon had on the community:

The salmon gave us a connection as community members and revitalized the community. We nurtured the salmon. It was like a rebirth or a beginning. [Elder] Frank [Jermey] used to tell me that when he was a boy the river was teeming with salmon. You could look into the river and see them. When we released the salmon, it gave us hope that the rivers will be alive again. It brought people into our community. It gave us a new sense of ourselves as Mi'kmaw people, as a community that had something to offer. We had knowledge to share with others. It was the rebirth of the community. (personal communication, March 15, 2009)

The project ended with a ceremony and release of the salmon. Each person had a cup with 
two or three salmon in it. While waiting for the release, people looked at "their" fish, talked to them, showed them to other people, and strengthened the connection between humans and fish. The release ceremony included smudging, prayers, drumming and the offering of tobacco to acknowledge the spirit of the salmon. We had indeed learned in relationship with the salmon.

\section{Strand three: Relationships between adults and children}

The research addressed the needs of the community to have their children educated in culturally relevant ways and to have them learning culturally relevant knowledge. The salmon project promoted the community in playing a lead role in education not only as the site of the learning but also by sharing their teachings from Elders, traditional teachers, and storytelling. It was an opportunity for the community to contribute to the education of their own, as well as all other, children. If, as Marie Battiste (2008) writes, research with Indigenous peoples "should empower and benefit Indigenous communities and cultures, not just researchers, their institutions, or Canadian society" (p. 501), then one way of doing that is to work with children and youth.

Parents, grandparents, and extended family want the children and youth to get an education and do well in school. They want children to be happy and to have good lives, however that may be conceptualized. Adults have the understanding that the children and youth of today will be the adults and leaders of tomorrow. Hence, in working with children and youth, there is an important relationship between the present and the future, between what we do now and what happens in the next seven generations. Indigenous communities have a vested interest in the well being of their children and the coming generations of children and they are engaged in efforts that support children and youth. Mi'kmaw Chief Darlene Bernard of Lennox Island First Nation gives voice to the fundamental values of work with children: "At the

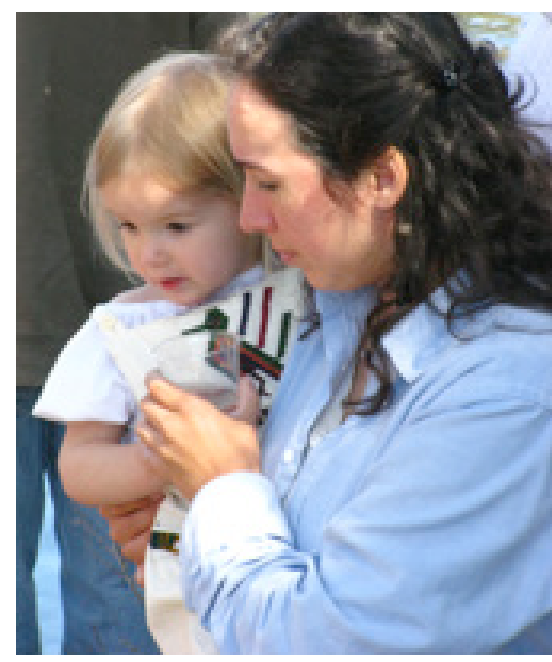

Figure 2: Mother and child (May 18, 2008) Credit: Salmon project team end of the day it's about the children; it's always about the children" (Atlantic Policy Congress of First Nations Chiefs Secretariat and Indian and Northern Affairs Canada, 2006, 0:20). The salmon project was open to all students and teachers as well as all community members and, as such, it was an opportunity for the adults to work together for children.

The research team and Mi'kmaw community members had also supported Mi'kmaw student Nicholas Whynot (Whynot \& Moore, 2003) in creating the video documentary A'tugwet, in which Wildcat community members shared stories about their traditions and experiences in the community. During the video production, community members were open to participating in the school project that extended learning in a Mi'kmaw studies course. The video was later 
issued by the Nova Scotia Department of Education as a learning resource for Nova Scotia schools.

Russell Bishop (2008) refers to "a culturally responsive pedagogy of relations" (p. 446) in which a positive relationship between the teachers and students is paramount to the engagement and success of students in learning. Taking students to the salmon project in Wildcat First Nation was an example of the teachers' efforts to work with the Mi'kmaw community to support student learning. I watched as the students arrived in Wildcat First Nation, stepped down from the bus, and rushed to the river's edge to explore. They viewed the salmon and commented on the changes since the last time they visited. The students listened as community members spoke, telling stories about salmon, the culture, and the community, thus demonstrating the "intergenerational communication of essential ideas" (Lanigan, 1998, p. 103).

Children and adults alike were excited on the day of the salmon release. Children spent time playing under the trees or looking for life that lives on the banks of the river. Parents held their young children, and teachers and parents closely supervised all students to ensure their safety along the water. The concern for the children and their learning was evident in the assurance that all children had cups containing salmon before the adults themselves took the remaining cups. Adults could be heard discussing the salmon with children and prompting their thoughts with talk of the growth of the salmon since hatching, the long journey the salmon undertake from the release site to the Atlantic Ocean, and thoughts of salmon safety in the river water. Adults further encouraged students' thinking with questions such as "Do you notice...? What do you think...? Can you imagine...?” These conversations were an indication of the adults' relationship with the children and their sense of responsibility for the children's learning.

The youngest students were the first to approach the water's edge, gently lowering their cups into the water and allowing the salmon to swim into the open water. Then older children released their salmon, and finally adults lowered their cups into the water. Immediately after the release, I noticed that some children stood quietly gazing at the river and others lingered by the shore to play in the water.

\section{Strand Four: The Relationship of People and the Land}

The traditional territory of the Mi'kmaq ${ }^{2}$ encompass the lands now called Nova Scotia, New Brunswick, the Gaspé Peninsula of Quebec, and Prince Edward Island. Wildcat First Nation is located in Kespukwitk, which is one of seven districts of the Mi'kmaw Nation. The Wildcat River, a tributary of the Medway River, flows through the community to the Atlantic Ocean.

The Wildcat River is one of several natal rivers, in the region, for Atlantic salmon. The concern for the salmon was, by default, also a concern for the environment in which they lived.

\footnotetext{
2 In explaining the proper use of the terms "Mi'kmaq" and "Mi'kmaw", the "Mi'kmaw Resource Guide" states "Mi'kmaq" refers to "The Family". Mi'kmaw is the singular form of the word and is also an adjective when it precedes a noun (eg. Mi'kmaw people) (p. 2). (The Union of Nova Scotia Indians, The Native Council of Nova Scotia, and The Confederacy of Mainland Mi'kmaq, n.d.).
} 
The adults and students alike could understand that humans impact the river. For example, pollution, acid rain, and forestry all affect the quality of the water in which the salmon live. Robin Wall Kimmerer defines watershed health as "a community of reciprocity, a place where all the pieces are intact and interact with one another in a mutually beneficial, reciprocal way" (Wall Kimmerer, 2012). Contemplating the health of the salmon habitat was a way that people became closer to the land. During one of the learning circles, participants walked along the river with Todd

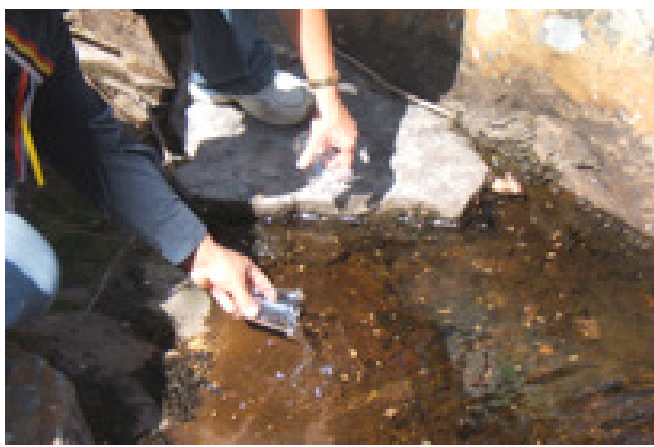

Releasing the salmon (May 18, 2008) Credit: Salmon project team as he talked about how plentiful salmon were during his childhood. Others joined in with their own stories of salmon size and population or with other stories of events that took place many years ago along the river. The past, the present, and place all connected people to time, land, and our human lives. While walking along the river that day, some speakers pointed out and told stories about the places of fast current as well as eddies and still ponds. There were also descriptions of how the river floods areas of land as the snow melts in the spring. This understanding helped people to know the nature of the river. During their visits, groups of students explored the river, the trees and bushes growing along its banks, the granite rocks protruding through the earth, and the occasional small gravel areas that allow one to stand barefoot at the water's edge. Everyone became more familiar with the river and the land.

Before the salmon release, biologists and Elders explained that the small salmon would do best if released in a place where the water was slow moving and vegetation was hanging over the bank. Walking along the shoreline looking for such a place on the day of the release was another opportunity for people to be in close contact with the river and the land. Fred Metallic (2008) describes the Mi'kmaw connection to the land when he writes:

in accepting that we have always lived from our land, in accepting that the land has taken care of us, we also accept that the land is a gift given to us by the Creator. By acknowledging the land in this way, we affirm our relationship to its beings. (p. 62)

\section{Concluding Comments}

This educational research set out to explore the ways in which Mi'kmaw community members and school staff could collaborate to center and legitimate Indigenous knowledge in an education project focused on raising and releasing Atlantic salmon. The Mi'kmaw concept of msit no'kmaq (all my relations) provided a framework for this reflective writing that explored other relationships that strengthened people's engagement in the research. In addition to the relationships between adults, there were also adult and child, humans and salmon, and 
people and land connections that engaged participants in the educational needs of the present generation of children as well as the coming generations.

\section{About the Author}

Sylvia Moore is a mother and grandmother in a Mi'kmaw family and is an Assistant Professor of Aboriginal Community-Based Education at Memorial University. Based at the Labrador Institute, she teaches in the Inuit Bachelor of Education program. Email: sylvia.moore@mun.ca

\section{References}

Archibald, J. (1997). Coyote learns to make a story basket: The place of First Nations in education (Unpublished doctoral dissertation). Simon Fraser University. Burnaby, British Columbia.

Atlantic Policy Congress of First Nations Chiefs Secretariat and Indian and Northern Affairs Canada (Director) \& Learning Resources and Technology, Nova Scotia Department of Education (Producer). (2006). Meeting of Nations. [Video]. Halifax, NS: Nova Scotia Department of Education.

Battiste, M. (2008). Research ethics for protecting Indigenous knowledge and heritage. In Denzin, N. K., Lincoln, Y. S., \& Smith, L. T. Handbook of critical and Indigenous methodologies (pp. 497- 509). Thousand Oaks, CA: Sage Publications, Inc.

Battiste, M. \& Henderson, J. Y. (2000). Protecting Indigenous knowledge and heritage: A global challenge. Saskatoon, SK: Purich Press.

Bishop, R. (2008). Te Kotahitanga: Kaupapa Māori in mainstream classrooms. In Denzin, N. K., Lincoln, Y. S., \& Smith, L. T. Handbook of critical and Indigenous methodologies (pp. 439- 458). Thousand Oaks, CA: Sage Publications, Inc.

Collaborative Salmon Initiative Planning Committee (2007). Dialogue on Plamu/ Atlantic Salmon in Cape Breton. (Report C0701). Unama'ki Institute for Natural Resources, NS: Bras d'Or Lakes Collaborative Environmental Planning Initiative.

Deloria, V. Jr. (1999). Relativity, relatedness, and reality. In B. Deloria, K. Foehner, \& S. Scinta (Eds.), Spirit and reason: The Vine Deloria Jr. reader (pp. 32-39). Golden, CO: Fulcrum Publishing.

Graveline, F.J. (1998). Circle works: Transforming Eurocentric consciousness. Halifax, NS: Fernwood Publishing.

Jimenez Estrada, V. M. (2005). The tree of life methodology. The Australian Journal of Indigenous Education. 34, 44-52.

Engaged Scholar Journal: Community-Engaged Research, Teaching and Learning 
Kovach, M. (2005). Emerging from the margins: Indigenous methodologies. In L. Brown \& S. Strega (Eds.), Research as resistance: Critical, Indigenous, and anti- oppressive approaches (pp. 19-36). Toronto, Ontario, Canada: Canadian Scholars' Press.

Kovach, M. (2009). Being Indigenous in the academy. In A.M. Timpson (Ed.), First Nations First Thoughts. (pp. 51- 73), Vancouver, BC: UBC Press.

Lambert, L. (2014). Research for Indigenous survival: Indigenous research methodologies in the behavioural sciences. Pablo, MT: Salish Kootenai College Press.

Lanigan, M.A. (1998). Aboriginal pedagogy: Storytelling. In L. Stiffarm (Ed.), As we see... Aboriginal pedagogy (pp. 103-120). Winnipeg, MB: University Extension Press, University of Saskatchewan.

Metallic, F. (2008). Strengthening our relations in Gespe'gewa'gi. In L. Simpson (Ed.), Lighting the eighth fire: The liberation, resurgence, and protection of Indigenous nations (pp. 59-71). Winnipeg, MB: Arbeiter Ring Publishing.

Moore, S. (2012). A trickster tale about integrating Indigenous knowledge in university-based programs. Journal of Environmental Studies and Sciences, 2(4), 324-330.

Moore, S. (2017). Trickster chases the tale of education. Montreal, QC: McGill-Queens University Press.

Prosper, K., Paulette, J., \& Davis, A. (2004). Sharing is an inherent part of Mi'kmaq culture. Atlantic Fisherman (p. 8). December, 8.

Rigney, L I. (1999). Internationalization of an Indigenous anticolonial cultural critique of research methodologies: A guide to Indigenist research methodology and its principles. Wicazo Sa Review. 14 (2), 109-121.

Smith, L. T. (1999). Decolonizing methodologies: Research and Indigenous peoples. London, UK: Zed Books Ltd.

Steinhauer, E. (2002). Thoughts on an Indigenous research methodology. Canadian Journal of Native Education, 26 (2), 69-81.

The Union of Nova Scotia Indians, The Native Council of Nova Scotia, and The Confederacy of Mainland Mi'kmaq (n.d.). The Mi'kmaw resource guide. Truro, NS: Tripartite Education Working Committee.

Wall Kimmerer, R. (2012, July 4). Exploring the meaning of watershed health [Video]. Retrieved from https://www.youtube.com/watch?v=hunXHTWw3tQ

Whynot, N. (Producer), \& S. Moore (Director). (2003). A'tugwet: Discovering the culture that is immune to time. [Video]. Caledonia, NS: North Queens Schools Enrichment Group.

Wilson, S. (2001). What is an Indigenous research methodology? Canadian Journal of Native Education, 25 (2), 175-179.

Wilson, S. (2008). Research is ceremony: Indigenous research methods. Black Point, Nova Scotia: Fernwood Publishing. 